\title{
PERILAKU BIDAN DALAM PELAKSANAAN INISIASI MENYUSU DINI DI WILAYAH KERJA PUSKESMAS II TAMBAK, PUSKESMAS BANYUMAS DAN PUSKESMAS I KEMRANJEN
}

\author{
Sumiyati ${ }^{1}$, Ova Emilia ${ }^{2}$, Djaswadi Dasuki ${ }^{3}$
}

\begin{abstract}
Background: Early Initiation of Breastfeeding (EIB) is important because it can increase the success of exclusive breastfeeding and infant survival. However, the implementation of the EIB is still not optimal in Banyumas. One of the factors that support the success of EIB is the support of health workers, especially midwives. Central Bureau of Statistics of Banyumas regency in 2012 said that most of deliveries in Banyumas $78.52 \%$ in 2011 attended by midwives.

Objective: To determine the behavior of midwives in the implementation of Early Initiation of Breastfeeding at Work Area of Tambak Public Health Center Banyumas. Public Health Center and Kemranjen Public Center.

Methods: The study was cross sectional complemented with qualitative data. The experiment was conducted at the Working Area of Tambak II, Banyumas and Kemranjen I public healh centers with 38 midwives as subjects. Indepth interviews conducted to 6 midwives and 4 postpartum mothers.

Results and Discussion: There were a significant association between knowledge and attitudes of midwives to practice implementation of EIB, knowledgeable midwife tent to practice E.I.B 1.79 times higher than less knowledgeable midwife. Good attitude midwives 1.62 times more likely to support EIB practice.

Conclusion: The behavior of midwife in the implementation of the ElB practices is influenced by a good knowledge and attitudes that support the EIB. Factors that inhibit the EIB, included flat nipples exhaustment of postpartum mothers and lack of rest among health professionals when encountered prolong labor.
\end{abstract}

Keywords: knowledge, attitude, practice, midwife, early initiation of breastfeeding

\begin{abstract}
ABSTRAK
Latar Belakang: Inisiasi Menyusu Dini (IMD) penting karena dapat meningkatkan keberhasilan ASI eksklusif dan kelangsungan hidup bayi. Namun pelaksanaan IMD masih belum optimal di Kabupaten Banyumas. Salah satu faktor yang mendukung keberhasilan IMD adalah dukungan tenaga kesehatan terutama bidan. Badan Pusat Statistik Daerah Kabupaten Banyumas tahun 2012 menyatakan sebagian besar penduduk Kabupaten Banyumas sekitar 78,52\% pada tahun 2011 menggunakan tenaga kesehatan bidan untuk menolong persalinan.

Tujuan: Untuk mengetahui perilaku bidan dalam pelaksanaan Inisiasi Menyusu Dini di Wilayah Kerja Puskesmas II Tambak, Puskesmas Banyumas dan Puskesmas I Kemranjen.

Metode: Penelitian observasional dengan rancangan cross sectional. Penelitian ini secara kuantitatif dan kualitatif. Penelitian dilaksanakan di Wilayah Kerja Puskesmas II Tambak, Puskesmas Banyumas dan Puskesmas I Kemranjen dengan subjek penelitian 38 bidan dan wawancara mendalam dengan 6 bidan serta 4 ibu postpartum.

Hasil dan Pembahasan: Hasil analisis bivariabel terdapat hubungan yang bermakna antara pengetahuan dan sikap bidan dengan pelaksanaan praktik IMD, bidan yang berpengetahuan baik 1,79 kali lebih besar untuk melakukan praktik IMD dengan baik dibandingkan dengan bidan yang berpengetahuan kurang. Sikap bidan yang mendukung IMD 1,62 kali lebih besar untuk melakukan praktik IMD dengan baik dibandingkan dengan sikap bidan yang tidak mendukung IMD.
\end{abstract}

Poltekkes Kemenkes Semarang

2,3 Bagian Obstetri dan Ginekologi, Fakultas Kdokteran Universitas Gadjah Mada 
Kesimpulan: Perilaku bidan dalam pelaksanaan praktik IMD dipengaruhi oleh pengetahuan yang baik dan sikap yang mendukung terhadap IMD. Faktor yang menghambat IMD antara lain bentuk puting yang mendatar sehingga bayi kesulitan untuk menghisap, ibu postpartum merasa capai dan lelah karena kurang istirahat serta faktor tenaga kesehatan, apabila menolong persalinan dengan kala II lama sehingga pelaksanaan IMD kurang dari satu jam.

Kata kunci: pengetahuan, sikap, praktik, bidan, inisiasi menyusu dini

\section{PENDAHULUAN}

Inisiasi Menyusu Dini (IMD) merupakan pemberian air susu ibu secara dini yang dilakukan segera setelah bayi lahir, tali pusat diikat, meletakkan bayi tengkurap di dada ibu dengan kulit bayi bersentuhan langsung dengan kulit ibu selama satu jam atau lebih sampai bayi dapat menyusu sendiri. ${ }^{1}$ Menyusu dini dapat mengurangi kematian neonatal dan postnatal. $^{2}$

Bidan sebagai ujung tombak pembangunan kesehatan yang berhubungan langsung dengan pelayanan kesehatan masyarakat dapat menjadi faktor pendukung atau pendorong namun juga dapat menjadi faktor penghambat keberhasilan program inisiasi menyusu dini. ${ }^{3}$

Badan Pusat Statistik Daerah Kabupaten Banyumas tahun 2012 menyatakan sebagian besar penduduk Kabupaten Banyumas sekitar 78,52\% pada tahun 2011 menggunakan tenaga kesehatan bidan untuk menolong persalinan. Tujuan penelitian ini untuk mengetahui perilaku bidan dalam pelaksanaan IMD di Wilayah Kerja Puskesmas II Tambak, Puskesmas Banyumas dan Puskesmas I Kemranjen.

\section{METODE}

Jenis penelitian ini merupakan penelitian observasional dengan rancangan cross sectional. ${ }^{4}$ Dilengkapi dengan data kualitatif. ${ }^{5}$ Populasi penelitian ini adalah semua bidan yang bekerja di wilayah Kerja Puskesmas II Tambak, Puskesmas Banyumas dan
Puskesmas I Kemranjen sebanyak 38 orang. Penelitian ini telah dilakukan pada bulan Oktober sampai Nopember 2013. Teknik pengambilan sampel menggunakan total sampling dari populasi.

Variabel penelitian meliputi: 1) variabel bebas: pengetahuan dan sikap bidan terhadap IMD; 2) variabel terikat: praktik bidan dalam pelaksanaan IMD; dan 3) variabel luar: karakteristik bidan meliputi umur, tingkat pendidikan, lama bekerja; promosi susu formula di PKD/Puskesmas/Bidan Praktik Mandiri (BPM).

Pengumpulan data kuantitatif melalui pengisian kuesioner dan data kualitatif dengan wawancara mendalam (indepth interview) kepada enam bidan mengenai faktor pendukung, faktor penghambat pelaksanaan IMD dan pengaruh promosi susu formula serta wawancara mendalam kepada empat ibu postpartum terhadap perilaku bidan dalam pelaksanaan praktik IMD.

Penelitian ini telah disetujui oleh Komisi Etik Penelitian Kedokteran dan Kesehatan Universitas Gadjah Mada No. KE/FK/896/EC tanggal 09 Oktober 2013.

\section{HASIL DAN PEMBAHASAN}

Penelitian ini dilakukan di Kabupaten Banyumas yaitu Wilayah Kerja Puskesmas II Tambak terdiri dari 7 bidan, Puskesmas Banyumas terdiri dari 18 bidan dan Puskesmas I Kemranjen terdiri dari 14 bidan, namun ada 1 bidan yang cuti menunaikan ibadah haji sehingga subjek penelitian sebanyak 38 bidan. 
Tabel 1. Karakteristik subjek penelitian

\begin{tabular}{lcr}
\hline \multicolumn{1}{c}{ Variabel } & $\begin{array}{c}\text { Jumlah } \\
\text { sampel }\end{array}$ & $\begin{array}{r}\text { Persentase } \\
\text { (\%) }\end{array}$ \\
\hline Pengetahuan & & \\
$\quad$ Baik & 27 & 71,05 \\
$\quad$ Kurang & 11 & 28,95 \\
Sikap & & \\
Mendukung & 21 & 55,26 \\
$\quad$ Tidak mendukung & 17 & 44,74 \\
Praktik IMD & & \\
Baik & 27 & 71,05 \\
Kurang & 11 & 28,95 \\
Umur bidan & & \\
$\geq 40$ tahun & 11 & 28,85 \\
$\quad<40$ tahun & 27 & 71,05 \\
Tingkat pendidikan & & \\
D3/D4 Kebidanan & 36 & 94,74 \\
D1 Kebidanan & 2 & 5,26 \\
Lama bekerja & & \\
$\quad \geq 10$ tahun & 22 & 57,89 \\
$<$ 10 tahun & 16 & 42,11 \\
Promosi susu formula & & 97,36 \\
Tidak & 37 & 2,63 \\
Ya & 1 &
\end{tabular}

Tabel 1 menunjukkan bahwa mayoritas bidan yang mempunyai pengetahuan baik tentang IMD mencapai $71,05 \%$, sebagian besar bidan mempunyai sikap mendukung terhadap IMD sebesar 55,26\%, mayoritas bidan telah melaksanakan praktik IMD dengan baik sebesar $71,05 \%$.

Hasil analisis bivariabel dapat dilihat pada tabel sebagai berikut:

\section{1). Hubungan antara Variabel Bebas dengan Variabel Terikat}

Tabel 2 menunjukkan terdapat hubungan yang bermakna statistik maupun praktis antara pengetahuan bidan tentang IMD dengan pelaksanaan praktik IMD ( $R P=1,79 ; 95 \% C l=1,06-3,02 ; p=0,026)$. Hal ini sesuai dengan penelitian sebelumnya bahwa bidan dengan skor pengetahuan yang tinggi akan melakukan praktik inisiasi menyusu dini dengan baik pada saat membantu ibu bersalin. ${ }^{6}$ Penelitian ini juga didukung hasil wawancara mendalam dengan bidan dan ibu postpartum bahwa bidan mempunyai pengetahuan yang baik tentang pengertian IMD. Berdasarkan hasil wawancara mendalam dengan salah satu informan berikut:

\section{"IMD adalah upaya untuk memberikan ASI sedini mungkin yang dilakukan pada saat bayi baru lahir, .... bayi suruh menyusu kira-kira satu jam..." (Bd. A).}

Bidan mempunyai pemahaman yang sama tentang IMD yaitu bayi mulai menyusu sendiri setelah lahir selama satu jam. Sesuai dengan pendapat yang menyatakan bahwa bidan telah membantu ibu dalam inisiasi menyusu dini dalam satu jam setelah melahirkan. ${ }^{7}$

Terdapat hubungan yang bermakna secara statistik maupun praktis antara sikap bidan terhadap IMD dengan pelaksanaan praktik IMD ( $R P=1,62 ; 95 \%$ $C l=1,00-2,62 ; p=0,027)$. Hasil penelitian ini sesuai dengan pernyataan bahwa sikap tenaga kesehatan merupakan salah satu faktor yang dapat mempengaruhi praktik pelayanan kesehatan dalam proses menyusui dan inisiasi menyusu dini. ${ }^{8}$ Penelitian ini didukung oleh penelitian lain bahwa tenaga professional kesehatan mempunyai sikap yang positif atau mendukung terhadap menyusui pada wanita berpenghasilan rendah, dengan menerapkan pengetahuan terhadap praktik inisiasi menyusu dini. ${ }^{9}$ Penelitian ini sesuai dengan pendapat bahwa tenaga kesehatan dianjurkan untuk mencipta-kan suasana yang tenang, nyaman dan penuh kesabaran untuk memberi kesempatan bayi merangkak mencari payudara ibu atau "the breast crawl". ${ }^{10}$ Berdasarkan wawancara mendalam menyatakan bahwa sikap bidan selama pelaksanaan IMD memberikan pelayanan kepada pasien baik, ramah, perhatian, sabar dan memberikan penyuluh-an tentang pemberian ASI Ekslusif, seperti ungkapan ibu postpartum berikut ini:

"...sikap bidan juga ramah, penuh perhatian, ramah, sabar, selalu mendampingi saya..."(Ny. NF). 
Tabel 2. Hubungan bebas dengan praktik IMD

\begin{tabular}{|c|c|c|c|c|c|c|c|c|}
\hline \multirow{3}{*}{ Variabel } & \multicolumn{4}{|c|}{ Praktik IMD } & \multirow{3}{*}{$x^{2}$} & \multirow{3}{*}{$p$} & \multirow{3}{*}{$R P$} & \multirow{3}{*}{$95 \% \mathrm{Cl}$} \\
\hline & \multicolumn{2}{|c|}{ baik } & \multicolumn{2}{|c|}{ kurang } & & & & \\
\hline & $\mathbf{n}$ & $\%$ & $\mathbf{n}$ & $\%$ & & & & \\
\hline \multicolumn{9}{|l|}{ Pengetahuan bidan } \\
\hline \multirow[t]{2}{*}{ Baik } & 22 & 81,48 & 5 & 18,52 & 4,9 & 0,026 & 1,79 & $1,06-3,02$ \\
\hline & & & & & 3 & & & \\
\hline Kurang & 5 & 45,45 & 6 & 54,55 & & & & \\
\hline \multicolumn{9}{|l|}{ Sikap bidan } \\
\hline \multirow[t]{2}{*}{ Mendukung } & 18 & 85,71 & 3 & 14,29 & 4,9 & 0,027 & 1,62 & $1,01-2,62$ \\
\hline & & & & & 1 & & & \\
\hline Kurang men dukung & 9 & 52,94 & 8 & 47,06 & & & & \\
\hline
\end{tabular}

\section{2). Hubungan antara Variabel Luar dengan Variabel Terikat}

Tabel 3. Hubungan variabel luar dengan praktik IMD

\begin{tabular}{|c|c|c|c|c|c|c|c|c|}
\hline \multirow{3}{*}{ Variabel } & \multicolumn{4}{|c|}{ Praktik IMD } & \multirow{3}{*}{$x^{2}$} & \multirow{3}{*}{$p$} & \multirow{3}{*}{$R P$} & \multirow{3}{*}{$95 \% \mathrm{Cl}$} \\
\hline & \multicolumn{2}{|r|}{ baik } & \multicolumn{2}{|c|}{ kurang } & & & & \\
\hline & $\mathbf{n}$ & $\%$ & $\mathbf{n}$ & $\%$ & & & & \\
\hline \multicolumn{9}{|l|}{ Umur bidan } \\
\hline$\geq 40$ tahun & 9 & 81,82 & 2 & 18,18 & 0,87 & 0,35 & 1,23 & $0,83-1,80$ \\
\hline$<40$ tahun & 18 & 66,67 & 9 & 33,33 & & & & \\
\hline \multicolumn{9}{|l|}{ Tingkat pendidikan } \\
\hline D3/D4 Kebidanan & 25 & 69,44 & 11 & 30,56 & 0,86 & 0,35 & 0,69 & $0,56-0,86$ \\
\hline D1 Kebidanan & 2 & 100,00 & 0 & 0 & & & & \\
\hline \multicolumn{9}{|l|}{ Lama bekerja } \\
\hline$\geq 10$ tahun & 19 & 86,36 & 3 & 13,64 & 5,95 & 0,02 & 1,73 & $1,03-2,90$ \\
\hline$<10$ tahun & 8 & 50,00 & 8 & 50,00 & & & & \\
\hline \multicolumn{9}{|l|}{ Promosi susu formula } \\
\hline Tidak & 27 & 72,97 & 10 & 27,03 & 2,52 & 0,11 & - & - \\
\hline $\mathrm{Ya}$ & 0 & 0 & 1 & 100,00 & & & & \\
\hline
\end{tabular}

Tabel 3 menunjukkan lama bekerja bidan bermakna secara statistik maupun secara praktis dengan pelaksanaan praktik IMD $(R P=1,73 ; 95 \%$ $C l=1,03-2,90 ; p=0,02)$. Penelitian ini bidan dengan pengalaman kebidanan selama 11-15 tahun dan $>15$ tahun mempunyai skor praktik inisiasi menyusu lebih tinggi dibandingkan bidan dengan pengalaman $<10$ tahun. ${ }^{6}$ Penelitian ini juga didukung oleh hasil penelitian sebelumnya bahwa ada hubungan yang bermakna antara lama kerja dengan kinerja bidan dalam pelaksanaan IMD di RSIA Budi Kemuliaan Jakarta, $(p=0,000) .{ }^{11}$ 


\section{3). Hubungan antara variabel luar dengan variabel bebas}

Tabel 4. Hubungan Variabel Luar dengan Pengetahuan Bidan tentang IMD

\begin{tabular}{|c|c|c|c|c|c|c|c|c|}
\hline \multirow{3}{*}{ Variabel } & \multicolumn{4}{|c|}{ Pengetahuan bidan } & \multirow{3}{*}{$x^{2}$} & \multirow{3}{*}{$p$} & \multirow{3}{*}{$R P$} & \multirow{3}{*}{$95 \% \mathrm{Cl}$} \\
\hline & \multicolumn{2}{|c|}{ baik } & \multicolumn{2}{|c|}{ kurang } & & & & \\
\hline & $n$ & $\%$ & $\mathbf{n}$ & $\%$ & & & & \\
\hline \multicolumn{9}{|l|}{ Umur bidan } \\
\hline$\geq 40$ tahun & 7 & 63,64 & 4 & 36,36 & 0,41 & 0,52 & 0,86 & $0,52-1,41$ \\
\hline$<40$ tahun & 20 & 74,07 & 7 & 25,93 & & & & \\
\hline \multicolumn{9}{|l|}{ Tingkat pendidikan } \\
\hline D3/D4 Kebidanan & 25 & 69,44 & 11 & 30,56 & 0,86 & 0,35 & 0,69 & $0,56-0,86$ \\
\hline D1 Kebidanan & 2 & 100,00 & 0 & 0 & & & & \\
\hline \multicolumn{9}{|l|}{ Lama bekerja } \\
\hline$\geq 10$ tahun & 18 & 81,82 & 4 & 18,18 & 2,94 & 0,09 & 1,45 & $0,90-2,34$ \\
\hline$<10$ tahun & 9 & 56,25 & 7 & 43,75 & & & & \\
\hline \multicolumn{9}{|l|}{ Promosi susu formula } \\
\hline Tidak & 26 & 70,27 & 11 & 29,73 & 0,42 & 0,52 & 0,70 & $0,57-0,87$ \\
\hline $\mathrm{Ya}$ & 1 & 100,00 & 0 & 0 & & & & \\
\hline
\end{tabular}

Tabel 4 menunjukkan bahwa tidak terdapat hubungan yang bermakna antara umur bidan dengan pengetahuan bidan tentang IMD $(p=0,52)$. Tidak terdapat hubungan yang bermakna tingkat pendidikan bidan dengan pengetahuan bidan tentang IMD $(p$
$=0,35)$. Tidak terdapat hubungan yang bermakna lama bekerja bidan dengan pengetahuan bidan tentang IMD $(p=0,09)$. Tidak terdapat hubungan yang bermakna promosi susu formula dengan pengetahuan bidan $(p=0,52)$.

Tabel 5. Hubungan variabel luar dengan sikap bidan terhadap IMD

\begin{tabular}{|c|c|c|c|c|c|c|c|c|}
\hline \multirow{3}{*}{ Variabel } & \multicolumn{4}{|c|}{ Sikap bidan } & \multirow{3}{*}{$x^{2}$} & \multirow{3}{*}{$p$} & \multirow{3}{*}{$R P$} & \multirow{3}{*}{$95 \% \mathrm{Cl}$} \\
\hline & \multicolumn{2}{|c|}{$\begin{array}{c}\text { Men- } \\
\text { dukung }\end{array}$} & \multicolumn{2}{|c|}{$\begin{array}{c}\text { Tidak } \\
\text { mendukung }\end{array}$} & & & & \\
\hline & $\mathrm{n}$ & $\%$ & $\mathbf{n}$ & & & & & \\
\hline \multicolumn{9}{|l|}{ Umur bidan } \\
\hline$\geq 40$ tahun & 10 & 90,91 & 1 & 9,09 & 7,96 & 0,005 & 2,23 & $1,36-3,65$ \\
\hline$<40$ tahun & 11 & 40,74 & 16 & 59,26 & & & & \\
\hline \multicolumn{9}{|l|}{ Tingkat pendidikan } \\
\hline D3/D4 Kebidanan & 20 & 55,56 & 16 & 44,44 & 0,024 & 0,88 & 1,11 & $0,27-4,58$ \\
\hline D1 Kebidanan & 1 & 50,00 & 1 & 50,00 & & & & \\
\hline \multicolumn{9}{|l|}{ Lama bekerja } \\
\hline$\geq 10$ tahun & 16 & 72,73 & 6 & 27,27 & 6,44 & 0,011 & 2,33 & $1,08-5,03$ \\
\hline$<10$ tahun & 5 & 31,25 & 11 & 68,75 & & & & \\
\hline \multicolumn{9}{|l|}{ Promosi susu formula } \\
\hline Tidak & 21 & 56,76 & 16 & 43,24 & 1,27 & 0,26 & - & - \\
\hline Ya & 0 & 0 & 1 & 100,00 & & & & \\
\hline
\end{tabular}

Tabel 5 menunjukkan terdapat hubungan yang bermakna secara statistik maupun praktis antara umur bidan dengan sikap bidan yang mendukung pelaksanaan IMD ( $R P=2,23 ; 95 \% C l=1,36-3,65 ; p$
$=0,005)$. Penelitian ini didukung oleh penelitian sebelumnya yang menyatakan rata-rata umur bidan 41,07 tahun (23-67 tahun, SD = 8,39), rata-rata mempunyai pengalaman sebagai bidan 12,74 tahun. 
Bidan telah melakukan dan mendukung pada ibu untuk Inisiasi Menyusu Dini. ${ }^{12}$ Terdapat hubungan yang bermakna secara statistik maupun praktis antara bidan yang telah lama bekerja dengan sikap bidan terhadap IMD ( $R P=2,33 ; 95 \% C l=1,08-5,03 ; p$ $=0,011)$. Penelitian ini sesuai dengan pendapat bahwa pembentukan sikap tidak hanya ditentukan oleh keadaan obyek yang dihadapi, tetapi juga ditentukan oleh pengalaman, situasi saat ini dan harapan seseorang di masa yang akan datang. Semakin lama bekerja sebagai bidan semakin banyak pengalaman yang dimiliki. ${ }^{13}$

Tabel 6. Analisis regresi logistik hubungan pengetahuan bidan, sikap bidan dengan pelaksanaan praktik IMD dengan mengontrol variabel luar

\begin{tabular}{|c|c|c|}
\hline Variabel & $\begin{array}{c}\text { Model } 1 \\
\text { OR } \\
\text { (Cl 95\%) }\end{array}$ & $\begin{array}{c}\text { Model } 2 \\
\text { OR } \\
\text { (Cl 95\%) }\end{array}$ \\
\hline \multicolumn{3}{|l|}{ Pengetahuan bidan } \\
\hline Baik & 5,32 & 4,11 \\
\hline Kurang & $1,00-28,13$ & $0,71-23,57$ \\
\hline \multicolumn{3}{|l|}{ Sikap bidan } \\
\hline Mendukung & 5,37 & 3,43 \\
\hline Tidak mendukung & $1,02-28,24$ & $0,57-20,70$ \\
\hline \multicolumn{3}{|l|}{ Lama bekerja } \\
\hline$\geq 10$ tahun & & 3,05 \\
\hline$<10$ tahun & & $0,51-18,35$ \\
\hline$R^{2}$ & 0,20 & 0,23 \\
\hline Deviance & 36,62 & 35,15 \\
\hline
\end{tabular}

Keterangan: OR: Odd Ratio; 95\% CI: 95\% Confidence Interval; $R^{2}$ : Koefisien determinasi

Analisis multivariat pada model 1 menunjukkan hubungan yang bermakna secara statistik maupun secara praktis antara pengetahuan, sikap bidan terhadap IMD dengan pelaksanaan praktik IMD, dimana kontribusi variabel pengetahuan yang baik dan sikap bidan yang mendukung IMD dapat memprediksi pelaksanaan praktik IMD dengan baik sebesar $20 \%$. Penelitian ini sejalan dengan penelitian sebelumnya bahwa pengetahuan, sikap dan keterampilan tenaga kesehatan sangat penting dalam mendukung praktik pemberian ASI terutama inisiasi menyusu dini. Tenaga kesehatan memiliki pengetahuan yang baik tentang inisiasi menyusu dini yang disertai keterampilan yang tepat dapat menyebabkan sikap yang mendukung terhadap inisiasi menyusu dini. ${ }^{14}$
Model 2 menunjukkan hubungan variabel bebas (pengetahuan dan sikap bidan) dengan variabel terikat (pelaksanaan praktik IMD) dengan mengikutsertakan variabel luar (lama kerja bidan). Hasil analisis menyatakan ada hubungan yang bermakna secara praktis tetapi tidak bermakna secara statistik, antara pengetahuan bidan, sikap bidan terhadap IMD dengan lama bekerja bidan terhadap pelaksanaan praktik IMD, dimana bidan yang lama bekerja $\leq 10$ tahun mempunyai kesempatan 3,05 kali lebih besar untuk melaksanakan praktik IMD. Model ini dapat memprediksi pelaksanaan praktik IMD sebesar 23\%.

Faktor-faktor yang mendukung pelaksanaan IMD antara lain faktor fisik dan psikologis ibu postpartum, 
dukungan suami, anggota keluarga dan pengetahuan tenaga kesehatan. Pemberian pendidikan kesehatan pada saat antenatal care (ANC) sehingga ibu hamil mengetahui bahwa setelah bayi baru lahir segera dilakukan IMD. Pernyataan ini sesuai penelitian Baker dkk yang menyatakan bahwa inisiasi menyusu akan berhasil dan mudah dilakukan ketika seorang ibu siap secara fisik dan psikologis saat kelahiran, adanya informasi dan dukungan serta percaya diri pada kemampuan untuk menyusui dan perawatan bayi baru lahir. ${ }^{15}$ Strategi pertama dalam inisiasi menyusu dini harus dimulai selama perawatan prenatal atau antenatal care, pendidikan kesehatan dan diskusi antara pasien dan tenaga kesehatan tentang IMD. ${ }^{16}$ Pernyataan ini seperti yang diungkap-kan oleh satu informan berikut ini:

“...faktor yang mendukung IMD ... terutama pengetahuan dari tenaga kesehatan, ibu hamil... dapat informasi saat ANC, sosialisasi itu tentang IMD, persiapan fisik dan psikologi ibu selama awal kehamilan .....faktor keluarga dan suami juga mendukung...."(Bd. B).

Faktor yang menghambat pelaksanaan IMD diantaranya ibu postpartum capai dan lelah karena kurang istirahat, dari sisi tenaga kesehatan apabila menolong persalinan lebih dari satu dalam waktu yang bersamaan, atau persalinan dengan kala II lama maka ingin segera menyelesaikan pertolongan persalinan sehingga pelaksanaan IMD kurang dari satu jam. Bentuk puting yang pendek dan masuk sehingga bayi kesulitan untuk menghisap. Pernyataan ini sesuai dengan penelitian bahwa tenaga kesehatan dan pembuat kebijakan mempunyai alasan wanita tidak memulai menyusu dini dan IMD tertunda disebabkan adanya keyakinan ibu perlu untuk istirahat setelah melahirkan. ${ }^{17}$ Sesuai dengan penelitian Forster \& McLachlan bahwa faktor risiko pelaksanaan IMD kurang berhasil disebabkan provider yang sibuk dengan waktu yang sangat sedikit dan faktor risiko pada saat persalinan ibu mengalami fase atau kala dua lama sehingga tidak dilakukan IMD. ${ }^{18} \mathrm{Hal}$ tersebut sesuai dengan ungkapan informan berikut: "....pelaksananaan IMD waktu kurang darisatu jam.... karena capek, misalkan kala duanya lama, cepat-cepat ingin menyelesaikan pekerjaan kita. Salah satu penghambat IMD... terutama pasien.... bu.... saya kesel (capek) lah..... sehingga sebentar pelaksanaan IMD..... ibunya capek, kurang istirahat, lelah...."(Bd. C).

"....hambatan inisiasi menyusu dini bentuk puting yang sebelah kanan agak pendek, kecil dan masuk bu..., jadi agak susah bayi mencaricari putting dulu, kalau yang kiri bayi bisa langsung menghisap.." (Ny. NF).

\section{KESIMPULAN DAN SARAN}

Perilaku bidan dalam pelaksanaan praktik IMD dipengaruhi oleh pengetahuan yang baik dan sikap yang mendukung terhadap IMD. Faktor yang mendukung pelaksanaan IMD antara lain faktor fisik dan psikologis ibu postpartum, dukungan suami, anggota keluarga dan pengetahuan tenaga kesehatan serta pemberian pendidikan kesehatan oleh bidan pada saat antenatal care maupun saat persalinan. Faktor yang menghambat IMD yaitu bentuk puting yang mendatar sehingga bayi kesulitan untuk menghisap, ibu postpartum merasa capai dan lelah karena kurang istirahat serta tenaga kesehatan apabila menolong persalinan dengan kala II lama sehingga pelaksanaan IMD kurang dari satu jam.

Berdasarkan hasil penelitian ini diharapkan perlu sosialisasi melalui pelatihan, seminar maupun whorkshop bagi tenaga kesehatan tentang IMD, perlu peningkatan komitmen tenaga kesehatan pada saat menolong persalinan untuk melaksanakan IMD secara tepat dan benar. Dinas Kesehatan Kabupaten disarankan untuk mengadakan evaluasi pelaksanaan IMD melalui supervisi secara rutin. Meningkatkan frekuensi penyuluhan dan konseling tentang IMD pada saat melakukan ANC, saat menolong persalinan baik kepada ibu hamil, anggota keluarga serta masyarakat. Saat melakukan ANC pada ibu hamil perlu dilakukan pemeriksaan payudara untuk mengetahui bentuk puting dan memberikan 
penjelasan mengenai cara perawatan payudara di Trimester III.

\section{DAFTAR PUSTAKA}

1. Vieira TO, Vieira GO, Giugliani ERJ, Mendes CM, Martins CC, Silva LR. Determinants of breastfeeding initiation within the first hour of life in a Brazilian population: cross-sectional study. BMC Public Health 2010;10(760):1-6.

2. Örün E, Yalçýn SS, Madenda Y, Üstünyurt-Eras Z. Factors associated with breastfeeding initiation time in a Baby-Friendly Hospital. The Turkish Journal of Pediatrics. 2010;10(1):10-6.

3. Kemenkes RI. Asuhan Persalinan Normal. Jakarta: Perkumpulan Obstetri dan Ginekologi Indonesia; 2010.

4. Murti B. Prinsip dan Metode Riset Epidemiologi. Pertama ed. Yogyakarta: Gadjah Mada University Press; 1997.

5. Creswell JW. Research Design, Quantitative \& Qualitative Approaches. New Delhi: Sage Publication, Inc; 1994.

6. Creedy DK, Cantrill RM, Cooke M. Assessing midwives' breastfeeding knowledge: Properties of the Newborn Feeding Ability questionnaire and Breastfeeding Initiation Practices scale. International Breastfeeding Journal. 2008;3(7):1-12.

7. Gangal P, Bhagat K, Prabhu S, Nair R. Breast Crawl: Initiation of Breastfeeding by Breast Crawl. India: UNICEF; 2007.

8. Queensland Maternity and Neonatal Clinical GP. Breastfeeding initiation. Queensland Maternity and Neonatal Clinical Guidelines Program [Internet]. 2010. Available from: http//ww.health.qld.gov.au/ qcq.

9. Entwistle F, Kendall S, Mead M. The promotion of breastfeeding among low-income women: midwives' knowledge and attitudes following a WHO/UNICEF breastfeeding management course. Evidence Based Midwivery. 2007;5(1):29-34.

10. Roesli U. Panduan Inisiasi Menyusu Dini Plus ASI Eksklusif. Jakarta: Pustaka Bunda; 2012. 76 p.

11. Setiarini T. Faktor-faktor yang berhubungan dengan Kinerja Bidan dalam Pelaksanaan Inisiasi Menyusu Dini di RSIA Budi Kemuliaan Jakarta. Jakarta: Universitas Indonesia; 2012.

12. Cantrill R, Creedy D, Cooke M. Midwives' knowledge of newborn feeding ability and reported practice managing the first breastfeed. Breastfeeding review: professional publication of the Nursing Mothers' Association of Australia. 2004;12(1):25-33.

13. Azwar S. Sikap Manusia Teori dan Pengukurannya. Kedua ed. Yogyakarta: Pustaka Pelajar; 2011.

14. Priscilla V. Early breastfeeding practice in West Sumatra, Indonesia : determinants and interventions for promotion. 44th International Course in Health Development (ICHD) [Internet]. 2008; September 24, 2007 - September 12, 2008:[1-41 pp.].

15. Baker EJ, Sanei LC, Franklin N. Early Initiation of and Exclusive Breastfeeding in Large-scale Communitybased Programmes in Bolivia and Madagascar. Health Popul Nutr. 2006;24(4):530-9.

16. Sinusas K, Gagliardi A. Initial Management of Breastfeeding. American Family Physician. 2001;64(6):981-8.

17. Agyemang TC, Kirkwood B, Edmond K, Bazzano A, Hill Z. Early initiation of breast-feeding in Ghana: barriers and facilitators. Journal of Perinatology 2008;28,:S46-S52.

18. Forster DA, McLachlan HL. Breastfeeding Initiation and Birth Setting Practices: A Review of the Literature. Journal of Midwifery \& Women's Health. 2007;52(3):273-80. 